\title{
Effect of varying salt concentration on iridescence in precooked pork meat
}

\author{
Chiara Ruedt $^{1}$ (D) Monika Gibis ${ }^{1} \cdot$ Jochen Weiss $^{1}$
}

Received: 21 June 2021 / Revised: 12 August 2021 / Accepted: 14 August 2021 / Published online: 4 October 2021

(c) The Author(s) 2021

\section{Abstract}

The objective of this study was to investigate the effect of salt concentration on meat iridescence in cured cooked pork products. In addition, the influence of nitrite and pigmentary color on iridescence and its visual macroscopic perception was ascertained. Sample cubes from the pigs M. longissimus thoracis et lumborum were salted with either $\mathrm{NaCl}(20 \mathrm{~g} / \mathrm{kg}$, $40 \mathrm{~g} / \mathrm{kg}$ ) or nitrite curing salt $(6 \mathrm{~g} / \mathrm{kg}, 20 \mathrm{~g} / \mathrm{kg}$, and $40 \mathrm{~g} / \mathrm{kg})$ and subsequently cooked. Control samples were not salted. The effects of $\mathrm{NaCl}$ and curing salt on iridescence, instrumental color and microstructure were evaluated. Salt treatment significantly $(p<0.05)$ increased water-holding capacity, mean myofibers diameters and iridescence and reduced light scattering ( $L^{*}$ value). An iridescence limit was reached with the $20 \mathrm{~g} / \mathrm{kg}$ salt treatments. No differences between sodium chloride and nitrite curing salt were observed for both visual evaluation and colorimetry of the interference colors. Iridescence increases were attributed to a swelling of the myofilament lattice and thus reduction of intermyofibrillar spaces as well as an optical clearing of the myofibrils by dissolution of myofibrillar proteins that both reduce light scattering and allow more reflectance and interference to occur.

\section{Graphic abstract}
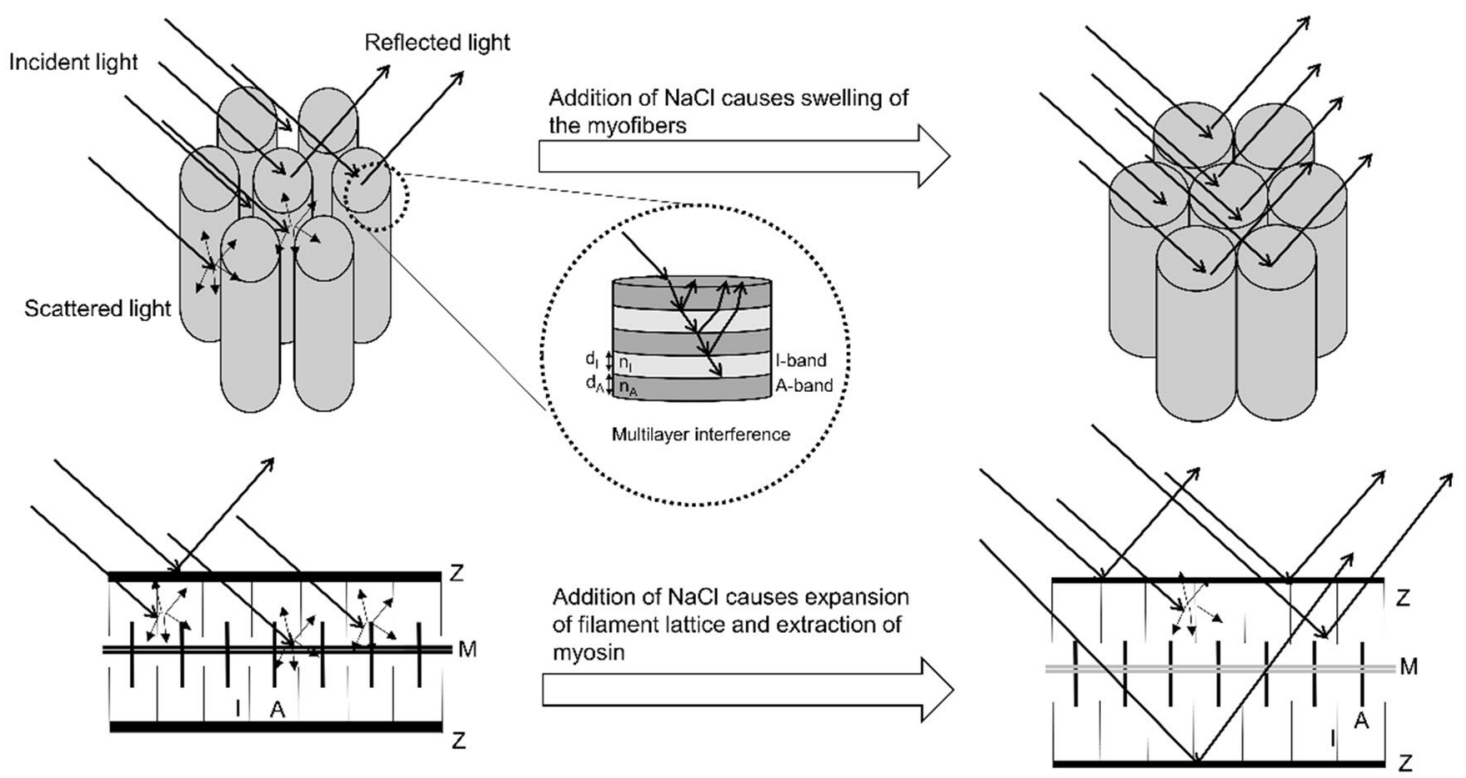

1 Light scattering from lattice and extracelluar space

$\downarrow$ Light scattering from lattice and extracelluar space

$\downarrow$ Fresnel reflectance

1 Fresnel reflectance

Keywords Iridescence $\cdot$ Meat color $\cdot$ Sodium chloride $\cdot$ Interference colors $\cdot$ Structural colors

Extended author information available on the last page of the article 


\section{Introduction}

Meat color is one of the primary factors influencing purchasing decisions of consumers. Color defects, such as discoloration or iridescence, can thus be reasons for product rejections. Iridescence is the brilliant, rainbowcolored shine often found in raw and precooked meats of different animal species (beef, pork, poultry, tuna, and venison) [1-5]. With the most common iridescent colors being green and yellow [6], consumers are often concerned about product quality and safety of meat products. They misinterpret iridescence often as microbial spoilage or addition of undesired chemical additives even though it is a physical phenomenon that has no real negative bearing on product edibility [7]. A reduction in the occurrence of iridescence would thus be beneficial since it would lead to less high-quality meat products being discarded.

Meat iridescence is a structural color which means that the color is produced from interactions of light with periodic micro- or nanoscale structures on the order of the wavelength of light and not from absorption as with pigmentary colors (e.g., red meat color from myoglobin). Structural colors can originate from different fundamental optical processes and their combinations: thin-film interference, multilayer interference, diffraction grating, photonic crystals or light scattering [8]. For meat iridescence, several reasons haven been proposed over the last decades. Ockerman [9] suggested that added salt scatters or disperses light into its constituent spectral colors (rainbow colors) like a prism. However, Wang [7] concluded that the prism effect resulting from added salt played a negligible role in iridescence as washing/soaking treatments intended to remove salt from the meat surface did not minimize the occurrence of iridescence [7]. In addition, iridescence is also noted in fresh meat and unseasoned meat products. Ockerman [9] and Warriss [10] proposed a thin fat film on the product's surface to cause iridescence by thin-film interference just like an oil film on water produces brilliant interference colors. These hypotheses were disproved since removal of fat or addition of vegetable oil did not alter iridescence [7]. The currently predominant hypothesis for meat iridescence is a surface diffraction grating from protruding myofibers [11]. However, this theory fails when it comes to explain why iridescence is still seen in tightly packaged products or underwater [12]. Recent studies $[3,13,14]$ have indicated that iridescence originates from multilayer interference from alternating stacks of A-bands (high refractive index) and I-bands (low refractive index) of striated muscle fibers. Therefore, it seems probable that structural changes of the myofibers and the myofilament lattice occurring during processing may have an effect on iridescence.
Sodium chloride is an essential multifunctional ingredient in meat products that is added to improve organoleptic properties, microbial safety, and technofunctionality such as water-holding capacity [15]. Chloride ions bind to the myofibrillar proteins (actin, myosin) and increase the negative net charge, and thereby the electrostatic repulsion [16] which causes the myofilaments to swell. This increase in the myofilament lattice spacing leads to transversal swelling of the myofibers [17]. Simultaneously, sodium chloride increases the solubility of myosin which causes structural changes to the myofibrils, such as extraction of the A-band, Z-lines and disruption of structures in the M-line [18]. Thereby the refractive index changes both within the myofibrils and the sarcoplasm. With the assumption that meat iridescence originates from reflections from sarcomere discs (A- and I-bands), such salt-induced alterations of the photonic structure should have an effect on iridescence. The manipulation of structural colors by changes in the periodic nanostructure (e.g., lattice distance) or the refractive index is widely known in organisms and photonic materials [19]. Interestingly, cooked cured products (e.g., pastrami, corned beef) and raw cured meats (e.g., Black Forest ham) are more prone to iridescence and show interference colors more vividly than fresh meat. This observation could indicate that salt plays an important role for the occurrence of iridescence.

The objective of this study was to investigate the effects of sodium chloride and nitrite curing salt on iridescence in sliced cooked pork products. Since the phenomenon of meat iridescence has received scant attention in the research literature and information on how processing variables contribute to iridescence on precooked pork is still scarce, we hope to shed more light on the mechanisms and structures underlying iridescence by investigating the effect of salt addition at different levels of iridescence. In turn, thus may open up new possibilities to reduce or eliminate its occurrence.

\section{Materials and methods}

\section{Sample preparation}

Fresh pork loins from three different carcasses were purchased from a local wholesaler (Mega eG, Stuttgart, Germany) and cut into cubes with side lengths of $5 \mathrm{~cm}$ from the inner core of the muscles. Since iridescence is significantly influenced by the cutting angle, the loin (M. lumborum et thoracis) was used since the uniform muscle fiber orientation allows for a consistent perpendicular cut to the fiber direction. Muscle $\mathrm{pH}$ was measured on fresh cut muscles using a pH-meter (WTW pH 537, Xylem Analytics Germany Sales GmbH \& Co. KG, Weilheim, Germany) equipped with a puncture type $\mathrm{pH}$ probe (WTW SenTix Sp, Xylem Analytics). The average fresh meat $\mathrm{pH}$ was $5.35 \pm 0.04$. 
Meat products most likely to display iridescence, e.g., raw cured ham or cooked pork ham are produced with curing salt and concentrations of $1.8 \mathrm{~g}$ to $3.5 \mathrm{~g} / 100 \mathrm{~g}$ of sodium chloride in the final product [20]. To evaluate the effect of sodium chloride on iridescence in cooked pork meat, five different salting treatments were performed: 2 $\mathrm{wt} \%$ ( $2 \mathrm{~g} \mathrm{NaCl}$ per $100 \mathrm{~g}$ fresh meat), $4 \mathrm{wt} \%$ sodium chloride, and $0.6 \mathrm{wt} \%, 2 \mathrm{wt} \%, 4 \mathrm{wt} \%$ nitrite curing salt (NCS). For the $2 \mathrm{wt} \%$ NCS treatment, a commercial nitrite curing salt (Zentrag eG, Frankfurt, Germany) with a $\mathrm{NaNO}_{2}$ concentration of $5 \mathrm{~g} / \mathrm{kg}$ was used. To eliminate a possible contribution of sodium nitrite to the iridescence effect, the nitrite concentration of the curing salts for the $0.6 \mathrm{wt} \%$ and $4 \mathrm{wt} \%$ NCS treatment were adjusted such that the salt addition resulted in a constant final concentration of $0.01 \mathrm{~g}$ $\mathrm{NaNO}_{2}$ per $100 \mathrm{~g}$ of fresh meat for all samples treated with curing salt. For that reason, the curing salt for the $4 \mathrm{wt} \%$ NCS treatment was a 1:1 mixture of the commercial nitrite curing salt and sodium chloride $(\mathrm{NaCl}$, Carl Roth $\mathrm{GmbH}+\mathrm{Co} . \mathrm{KG}$, Karlsruhe, Germany) resulting in a sodium nitrite concentration of $2.5 \mathrm{~g} \mathrm{NaNO}_{2} / \mathrm{kg}$ salt and the curing salt for the $0.6 \mathrm{wt} \% \mathrm{NCS}$ treatment was a mixture of sodium nitrite $\left(\mathrm{NaNO}_{2}\right.$, Merck KGaA, Darmstadt, Germany) and commercial nitrite curing salt resulting in a sodium nitrite concentration of $16.7 \mathrm{NaNO}_{2} / \mathrm{kg}$ salt. The different treatments used in this experiment correspond to salt concentrations typically found in those products. For the control treatment, no salt was added.

The salt was manually massaged into the fresh meat cubes and samples firmly packaged into plastic bags (HDPE $20 \mu \mathrm{m}$ ). Control samples were vacuum-packaged (vacuum machine Multivac Type C400, MULTIVAC $\mathrm{GmbH} \&$ Co. KG, Wolfertschwenden, Germany) into vacuum bags (PA/PE $90 \mu \mathrm{m}$, Mega eG, Stuttgart, Germany) to prevent spoilage. Samples were stored at $2{ }^{\circ} \mathrm{C}$ for 10 days to completely absorb the added salt and subsequently cooked in a cooking chamber (Ness-Smoke GmbH \& Co. KG, Remshalden, Deutschland) with saturated steam at $74{ }^{\circ} \mathrm{C}$ to a final core temperature of $70{ }^{\circ} \mathrm{C}$. The weight of the cubes was measured before and after cooking to calculate the cooking loss. After cooling at $2{ }^{\circ} \mathrm{C}, \mathrm{pH}$ values were measured and sample cubes were sliced perpendicular to the muscle fiber orientation from the center of the cubes with a slicing machine (Type VS8A, Bizerba SE \& Co. KG, Balingen, Germany) to a thickness of about $1 \mathrm{~cm}$. Two slices were packaged in vacuum bags (PA/PE $90 \mu \mathrm{m}$ ) and stored in the dark at $2{ }^{\circ} \mathrm{C}$ for sensory analysis, instrumental color measurements and confocal laser scanning microscopy. The remaining sample was finely comminuted (Blixer 2, Robot Coupe SA, France) and stored at $2{ }^{\circ} \mathrm{C}$ for subsequent chemical analysis.

\section{Cooking loss}

For determination of the cooking loss, the weights of the salted meat cubes $\left(m_{i}\right)$ and the weights of the cubes after cooking $\left(m_{c}\right)$ were measured and cooking loss calculated according to the following equation:

Cooking loss $(\%)=\frac{\left(m_{i}-m_{c}\right)}{m_{c}} \times 100 \%$

\section{Sensory analysis}

Slices were evaluated visually for iridescence extent (= surface area affected by iridescence) and intensity by panelists on an interval scale ranging from 0 (no iridescence, $0 \%$ of surface affected) to 10 (very strong iridescence, $100 \%$ of surface affected). The sensory panel was composed of 20 trained individuals from the Food Science Department. All panelists passed the Ishihara test for red-green color deficiencies. Direct illumination was realized by a light source (4.5 W, 220-240 V, $4000 \mathrm{~K}, \mathrm{CRI} \geq 80$, Osram Lich AG, Munich, Germany) adjustable in position. The panelists were instructed to set the illumination and rotate and tilt the samples to evaluate maximum iridescence. Prior to the testing, each panelist was trained individually on the sensory scale with reference images (Fig. 1) showing slices of iridescent cooked pork hams with a detailed description of the iridescent colors and the extent of iridescence as well as on the correct adjustment of the illumination and observation angle. Reference images as well as a reference sample showing very strong iridescence (9-10 intensity score, intensity and extent score indicated on the reference sample) were provided during the sensory evaluation. Each panelist evaluated four slices per treatment (from 3 different carcasses). The sample order was randomized. The final iridescence score was the average of the scores for intensity and extent of area. Scores of slices from the same carcass were averaged. As such, a total of three biological replicates were analyzed.

\section{Laser scanning microscopy and measurement of minimal Feret diameter}

Minimal Feret diameter was measured on the sample slices by confocal laser scanning microscopy. Circular samples with a diameter of $1.5 \mathrm{~cm}$ were stamped from the slices, covered with $20 \mu \mathrm{L}$ Calcoflour White Stain (Sigma-Aldrich Chemie GmbH, Taufkirchen, Germany), and left to soak in for at least $10 \mathrm{~min}$. Images $(1024 \times 1024$ pixels $)$ were acquired with a confocal laser scanning microscope (CLSM; Eclipse-C1, Nikon, Düsseldorf, Germany) equipped with a plan flour objective (CFI Plan Fluor 10×/0.30, Nikon, 


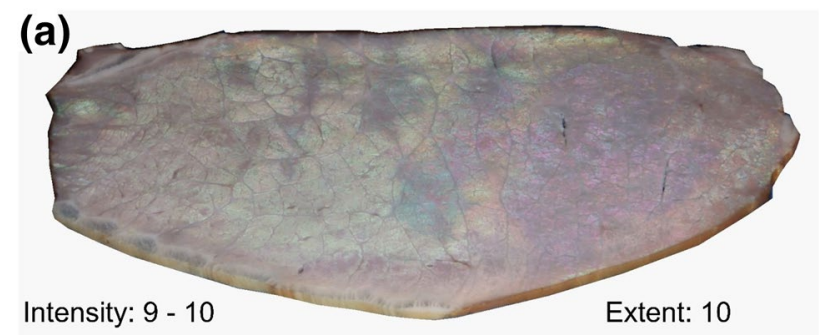

(b)

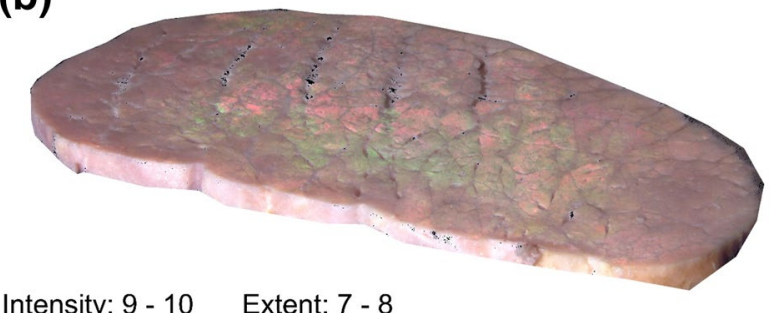

ntensity: 9 - $10 \quad$ Extent: 7 - 8

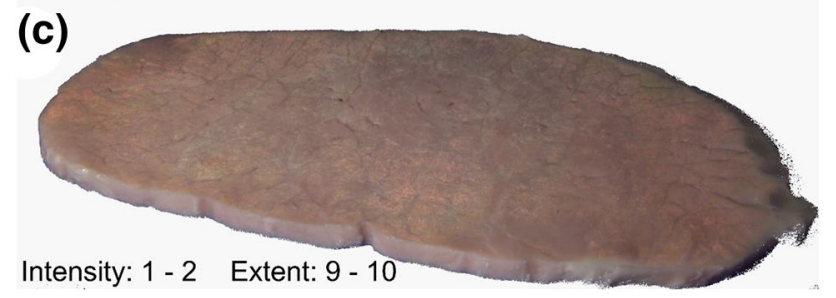

Fig. 1 Examples of reference images showing iridescent cooked ham samples with different iridescence intensities and extent that were used for panelist training on the sensory scale (ratio scale from 0 to 10). Iridescence was visually evaluated by the attributes "intensity" and "extent"

Düsseldorf, Germany) and NIS-Elements AR software (v5.01.00, Nikon). Calcofluor White was excited at $638 \mathrm{~nm}$ with a diode laser (Cobolt 06-MLD, Cobolt AB, Solna, Sweden). The minimal Feret diameter was measured by manually tracing 50 fibers per image from three different slices with three images per slice (a total of 450 fibers per treatment) with the software ImageJ 1.52t (Fiji implementation) [21]. Minimal Feret diameter as a measure of the muscle fiber size was used because of its robustness against fluctuations in the orientation of the sectioning angle.

\section{Instrumental color}

Instrumental color was determined on the sample slices by a colorimeter (Chroma Meter CR-400, Konica Minolta, Inc., Tokyo, Japan) with an $8 \mathrm{~mm}$ aperture, using the D65 illuminant and $2^{\circ}$ standard observer. The instrument was calibrated against a white standard tile. Color was measured in the CIE-LAB color space [22] and expressed in terms of lightness $L^{*}$, redness $a^{*}$ and yellowness $b^{*}$. Each value was the mean of three determinations on four different slices per salt treatment.

\section{Spectroscopy}

A spectrophotometer (Flame-S, $25 \mu \mathrm{m}$ slit, Ocean Optics B.V., Ostfildern, Germany) with a Sony ILX811B CC detector and a pulsed xenon-lamp (PX-2, Ocean Optics B.V., Ostfildern, Germany) were connected to a fiber optic reflection probe (AVA FCR-7UVIR200-2-ME, $6 \times 200 \mu$ m core illumination fibers, $1 \times 200 \mu \mathrm{m}$ measurement fiber, Avantes BV, Apeldoorn, The Netherlands). To record the specular reflectance of iridescence on cooked samples, the measuring geometry was adjusted by fixing the reflection probe in an oblique angle to the sample surface and rotating the sample on a stage (MAXYR-60R-P, Optics Focus Instruments Co, Ltd., Beijing, China) to the point of maximum iridescence (determined by the real-time spectrophotometer output). The system was standardized on Teflon tape (polytetrafluoroethylene; [3]). Reflectance spectra were recorded from 300 to $750 \mathrm{~nm}$ in $1.33 \mathrm{~nm}$ steps with the software Ocean View (v 1.6.7, Ocean Optics) and expressed as percent reflectance relative to the white standard. All measurements were performed in a dark room. For each spectrum, the average of 10 scans with an integration time of $5 \mathrm{~ms}$ was taken and three spectra were averaged. Chromaticity coordinates $x, y$ (CIE 1931) were calculated by Ocean View software $\left(2^{\circ}\right.$ standard observer, illuminant D65).

\section{Determination of moisture content}

The moisture content of samples was determined according to the official collection of methods of analysis $\$ 64$ (L 06.003 ) of the German Food and Feed Act [23]. Approximately $5 \mathrm{~g}$ of the samples were weighed onto $35 \mathrm{~g}$ of annealed silica sand (Carl Roth GmbH + Co. KG, Karlsruhe, Germany), rubbed, and dried in an oven for $4 \mathrm{~h}$ at $103 \pm 2{ }^{\circ} \mathrm{C}$. After that, samples were cooled down to room temperature using a desiccator, weighed and dried in the oven for another $30 \mathrm{~min}$. This procedure was repeated until a constant weight had been reached. The moisture content was calculated based on the mass loss after drying. Each sample was analyzed in triplicate.

\section{Determination of sodium chloride content}

Sodium chloride content was determined by the Volhard method according to the official collection of methods of analysis $\$ 64$ (L 06.00-5) of the German Food and Feed Act (LFGB) [23]. Approximately $10 \mathrm{~g}$ of sample was weighed into conical flasks and $100 \mathrm{~mL}$ of hot distilled water was added. The flasks were placed in a boiling water bath for $15 \mathrm{~min}$. After cooling to room temperature, $2 \mathrm{~mL}$ Carrez-I $\left(\mathrm{K}_{4}\left[\mathrm{Fe}(\mathrm{CN})_{6}\right] 3 \mathrm{H}_{2} \mathrm{O}, 106 \mathrm{~g} / \mathrm{L}\right.$, Carl Roth $\mathrm{GmbH}+\mathrm{Co} . \mathrm{KG}$, Karlsruhe, Germany) and Carrez-II $\left(\mathrm{Zn}\left(\mathrm{CH}_{3} \mathrm{COO}\right)_{2} \cdot 2 \mathrm{H}_{2} \mathrm{O}\right.$, 220 g/L, Carl Roth GmbH + Co. KG, Karlsruhe, Germany) 
solution was added and the flasks left at room temperature for $30 \mathrm{~min}$. Subsequently, the samples were transferred into $200 \mathrm{~mL}$ volumetric flasks, filled with distilled water to the mark, mixed and filtrated (Rotilabo-folded cellulose filters, type 113P, Carl Roth GmbH + Co. KG, Karlsruhe, Germany). After the addition of $5 \mathrm{~mL}$ of $4 \mathrm{M}$ nitric acid, $1 \mathrm{~mL}$ of indicator $\left(\left(\mathrm{NH}_{4}\right) \mathrm{Fe}\left(\mathrm{SO}_{4}\right)_{2} \cdot 12 \mathrm{H}_{2} \mathrm{O}\right.$, saturated solution, Acros Organics B.V.B.A., Fair Lawn, NJ, USA) and $20 \mathrm{~mL}$ of $0.1 \mathrm{M}$ silver nitrate $\left(\mathrm{AgNO}_{3}\right.$, Carl Roth $\mathrm{GmbH}+\mathrm{Co} . \mathrm{KG}$, Karlsruhe, Germany) standard solution to $20 \mathrm{~mL}$ of filtrate, the excess silver nitrate is back titrated with $0.1 \mathrm{M}$ potassium thiocyanate (KSCN, VWR International, LLC, Radnor, PA, USA) standard solution. The sodium chloride content was calculated from the volume of potassium thiocyanate needed for back titration as grams of $\mathrm{NaCl}$ per $100 \mathrm{~g}$ of sample. Three replicates were performed for each sample.

\section{Determination of protein}

Protein concentrations were measured by rapid nitrogen analysis according to the Dumas method $(\$ 64 \mathrm{~L} 01.00$ 60 ) with the Dumatherm N Pro (Gerhardt GmbH \& Co. KG, Königswinter, Germany) calibrated with EDTA (ethylenediaminetetraacetic acid, $\geq 99 \%$, p.a, ACS, Carl Roth $\mathrm{GmbH}+\mathrm{Co} . \mathrm{KG}$, Karlsruhe, Germany). A nitrogen to protein conversion factor of 6.25 for meat was used. Each sample was measured in triplicate.

\section{Statistical analysis}

Descriptive statistical analysis was performed by calculating means \pm 1 standard deviations (SD) for the three different carcasses $(n=3)$ within each treatment using Excel (Microsoft, Redmond, WA, USA). Sensory data from the panelists were averaged for each sample cube. Data were analyzed with the Shapiro-Wilk and Levene's test to test statistical assumptions. Data that met the assumption of normality and homoscedasticity were analyzed with one-way ANOVA (salt treatment as factor variable) and when $\mathrm{F}$ values were statistically significant $(p<0.05)$, Fisher's LSD post hoc test was applied to determine differences between treatment means. Data that did not meet the assumption of homoscedasticity were analyzed with Welch's ANOVA and Games-Howell post hoc test. Non-normally distributed data were analyzed with Kruskal-Wallis ANOVA and Dunn-Bonferroni post hoc analysis to test for differences among the groups. Differences in evaluations between samples from different carcasses were analyzed with Friedman's test and Dunn-Bonferroni post-hoc analysis. Spearman's correlation coefficient $\left(r_{\mathrm{s}}\right)$ was calculated between iridescence score and $\mathrm{pH}$, cooking loss, water content, $\mathrm{NaCl}$ content, colorimetric values and mean fiber diameter to test for relationships. A significance level of $\alpha=0.05$ was used for all statistical calculations. Significant differences $(p<0.05)$ were labeled with different letters. Data were analyzed using SPSS statistical software (SPSS 25, SPPSS Inc., IL, USA).

\section{Results and discussion}

Iridescence was observed in all samples before any treatment with primarily greenish, yellow colors and few pink spots. After dry-salting, greater iridescence was found in terms of both the area affected by iridescence and the intensity of the iridescent colors (Fig. 2). Samples treated with $0.6 \mathrm{wt} \%$ curing salt (NCS) exhibited weaker iridescence compared to the samples treated with higher amounts of salt. However, there were no apparent differences in iridescence between samples treated with $2 \mathrm{wt} \%$ and $4 \mathrm{wt} \%$ sodium chloride or nitrite curing salt. Iridescence shifted from the original greenish color in untreated samples to yellow, orange and mostly remained on the surfaces after the heating process. All sample slices cut transversely to muscle fiber direction from the samples core showed iridescence to varying degrees, depending on the salt treatment (Fig. 3). This finding contradicts the hypotheses of iridescence originating from salt crystals on the product surface [9] and is in agreement with observations made by Wang [7] who found that iridescence could not be eliminated by removal of salt from the samples' surfaces. Control samples (no salt added) had significantly $(p<0.05)$ less iridescence (iridescence score of $2.9 \pm 1.5)$ than samples treated with either sodium chloride or nitrite curing salt at higher levels. Iridescence scores increased with higher amounts of added salt. From all treated samples, lowest iridescence score $(6.0 \pm 1.5)$ was observed in the $0.6 \mathrm{wt} \%$ NCS treatment. Samples treated with $4 \mathrm{wt} \%$ sodium chloride were rated with the highest overall score $(8.7 \pm 1.0)$. However, no differences ( $p>0.05)$ were found between the $2 \mathrm{wt} \%$ $\mathrm{NCS}, 2 \mathrm{wt} \% \mathrm{NaCl}$ and $4 \mathrm{wt} \% \mathrm{NCS}$ and as well as between the $0.6 \mathrm{wt} \% \mathrm{NCS}$ and the $4 \mathrm{wt} \% \mathrm{NCS}$ treatments. The results from the sensory analysis of the cooked samples are mostly in accordance with the visual observations of the dry cured samples before cooking which indicates that cooking had no or little effect on meat iridescence. These results agree with Wang [7] who reported that iridescence was found both in raw and cooked meat, and assumed that raw meat might have the same level of iridescence as cooked meat since the striation pattern of A- and I-bands is still visible after cooking $[24,25]$.

Panelists differed in their evaluation of samples from different carcasses within the same treatment (Fig. 4). For instance, sample from carcass 3 was evaluated in the $4 \mathrm{wt} \%$ $\mathrm{NaCl}$ treatment with a lower score than the sample from carcass 1 and 2. However, it can be said that the carcasses within a treatment were mostly evaluated with a similar score. High standard deviations might be explained with an 

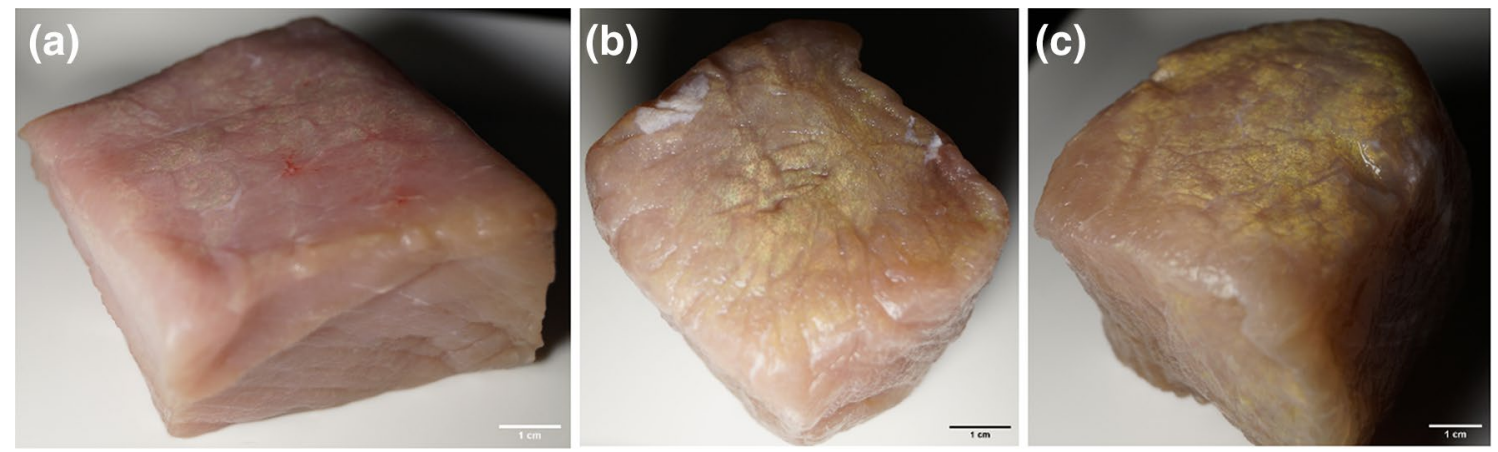
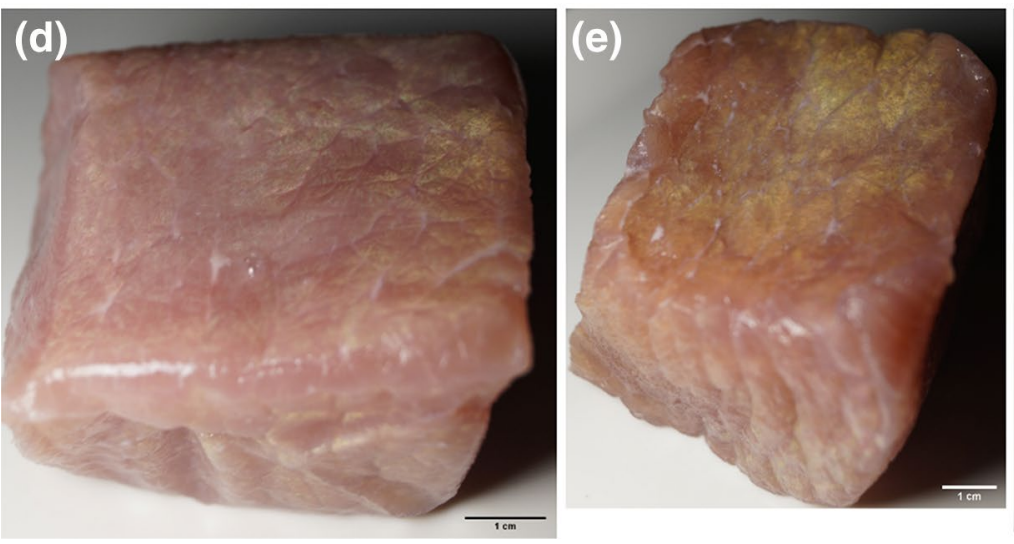

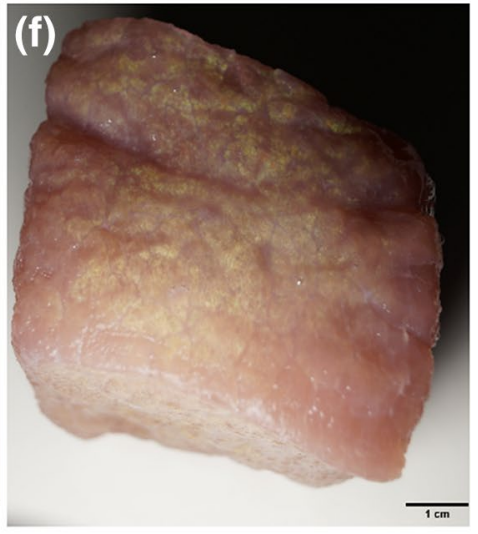

Fig. 2 Iridescence in meat cubes from the same pork loin (M. thoracis et lumborum) without salt (a) and dry-salted with sodium chloride $(\mathbf{b}, \mathbf{c})$ or nitrite curing salt $(\mathbf{d}, \mathbf{e})$ at varying salt concentrations after

individual sensitivity of the panelists towards iridescence [7] but can certainly also arise from limitations regarding standardization of the sensory analysis, especially the consistent evaluation of iridescence on the sensory scales. This drawback of the method could be overcome to a certain degree by a more extensive panel training or the use of a simplified sensory scale (e.g., an ordinal scale with the categories: no iridescence, weak iridescence, strong iridescence) that would, however, neglect the complexity of iridescence. The visual evaluation of meat iridescence is generally challenging due to the complex angle-dependency, the variety of interference colors and as mentioned above an individual sensitivity towards the interference colors. For example, it is conceivable that green iridescence that distinguishes strongly from the original product color is perceived much differently than an orange-red iridescence and thereby also evaluated differently. In addition, the samples did not show only one certain interference color but each slice showed a whole variety of colors that further complicated a standardized evaluation. It should be kept in mind that color is not just a physical property but a perceptual phenomenon that is affected by various factors such as gender [26], age [27] or hormones [26]. Iridescence evaluation can thus be biased between the individual panelists even with training and reference samples. However, sensory analysis is the only
10 days at $2{ }^{\circ} \mathrm{C}$ : (d) $0.6 \mathrm{wt} \%$, (b, e) $2 \mathrm{wt} \%$ and $4 \mathrm{wt} \%$ (c, f). Final nitrite concentration of the NCS samples was constant $\left(0.01 \mathrm{~g} \mathrm{NaNO}_{2}\right.$ per $100 \mathrm{~g}$ of fresh meat)

suitable method when investigating factors affecting iridescence since other methods either completely fail to measure iridescence (e.g., colorimeter with fixed measuring geometry) or they are limited to certain properties of iridescence (e.g., iridescence extent measured by digital image analysis or iridescence color and intensity measured by an optical fiber system).

Differences in iridescence have previously been reported for different muscles and between same muscles from different carcasses [2]. These carcass-to-carcass variations were observed even under the same cooking and slicing conditions [28] and when muscles were from animals with the same age, breed and nutritional value [7]. A possible explanation for these variations could be different structural or biochemical characteristics of the muscles [7]. Kukowski, Wulf [2] attributed iridescence differences between muscles to $\mathrm{pH}$. It seems more likely though that the iridescence differences observed in this study were caused by structural inhomogeneities, especially with respect to the cutting angle of the myofibrils. While samples from $M$. thoracis et lumborum were chosen because of the predominantly uniform muscle fiber orientation, it is not possible to perfectly cross-cut the myofibers in each sample in the same manner. Moreover, nitrite and the formation of the red curing color (nitrosyl myochromogen) did not influence the interference 


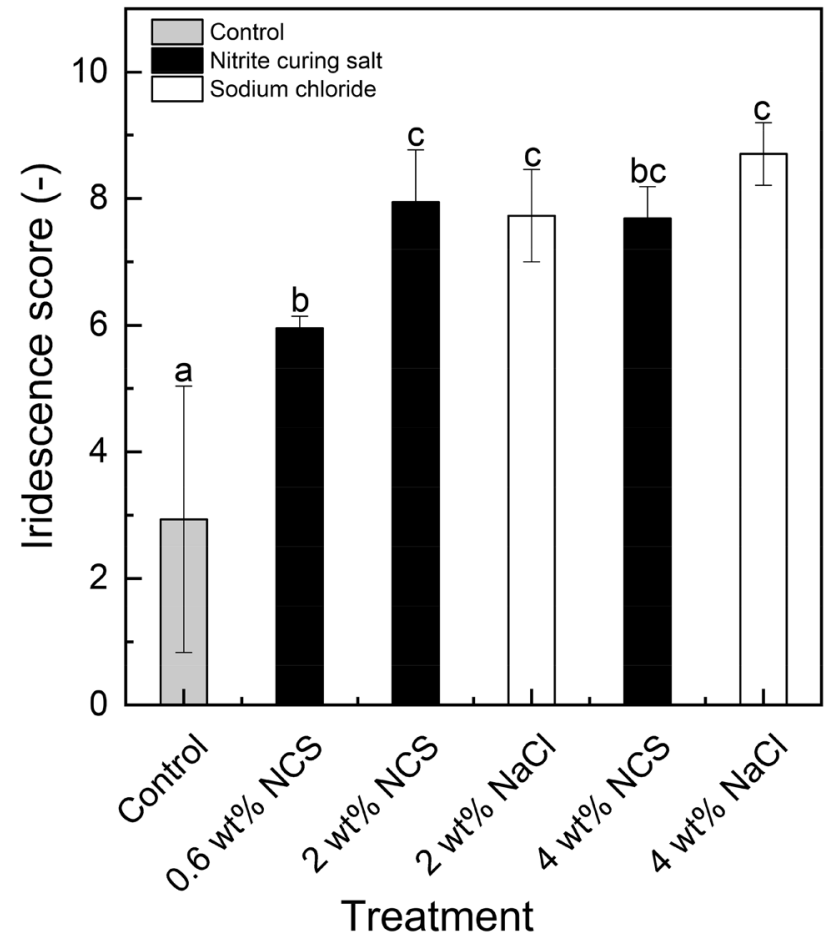

Fig. 3 Effect of salting treatment (NCS: curing salt) on iridescence score of cooked samples $(n=3)$ from pork $M$. longissimus thoracis et lumborum. Final nitrite concentration of the NCS samples was constant $\left(0.01 \mathrm{~g} \mathrm{NaNO}_{2}\right.$ per $100 \mathrm{~g}$ of fresh meat). Different letters indicate a significant difference $(p<0.05)$ between the treatments

colors itself nor the human perception of iridescence. No differences in sensory analysis were observed between the $\mathrm{NaCl}(2 \%, 4 \%)$ and the NCS $(2 \%, 4 \%)$ treatments.

Colorimetry of iridescent areas from different treatments showed very similar CIE chromaticity coordinates (Fig. 5) representing yellow interference colors that are in accordance with the macroscopic observations of a yellow-orange surface iridescence. Rotation of the sample caused either interference colors (within a narrow angular range) with hues on the periphery of the color gamut to appear, or diffuse reflectance in the central white area that represents macroscopic light scattering in meat to occur [29]. Reflectance spectra of iridescent areas from samples treated with $0.6 \%$, $2 \% \mathrm{NCS}$ or $4 \% \mathrm{NaCl}$ were all dominated by three interference peaks with one major peak at around $650 \mathrm{~nm}$, respectively, $700 \mathrm{~nm}$. These spectra are typical for iridescent meat or iridescent myofibers $[1,3,4,6]$.

The findings indicate that pigmentary color might be of no importance for meat iridescence although intensive interference colors are commonly seen in dark meat and meat products, e.g., cooked beef pastrami, corned beef [6], cooked duck meat or raw cured pork hams. Kukowski, Wulf [2] reported that higher iridescence score in beef semitendinosus was associated with higher $a^{*}$ and $b^{*}$ colorimeter
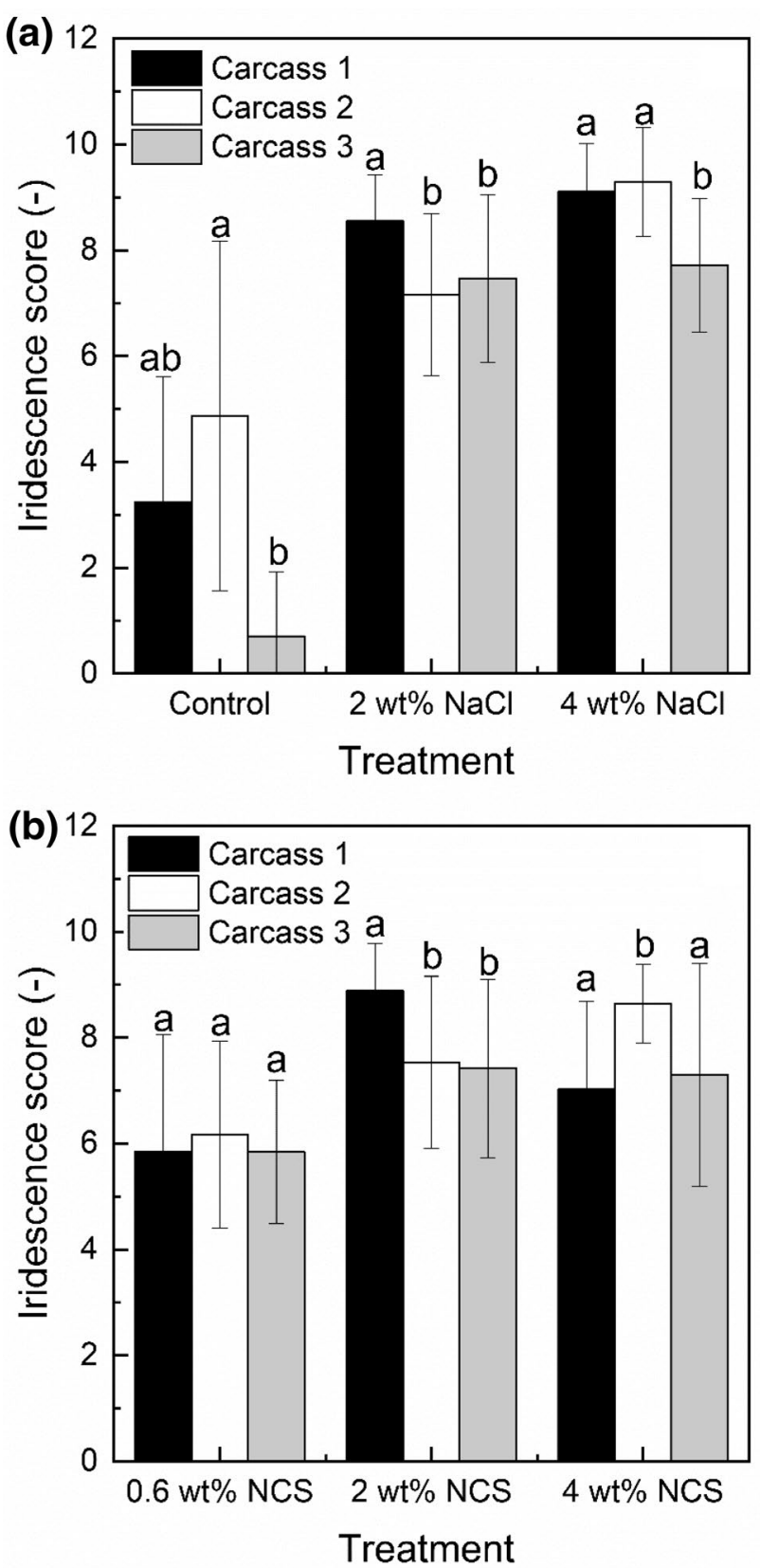

Fig. 4 Iridescence evaluation of cooked samples from pork $M$. longissimus thoracis et lumborum from different carcasses by a sensory panel $(n=20)$. Different letters indicate a significant difference $(p<0.05)$ between the evaluations within a treatment

values. Furthermore, it is well known that the color effects of butterfly scales or the cuticle of shield bugs are greatly intensified by an underlying dark, absorbing pigment screen that absorbs transmitted light and thereby provides a dark background against which the scattered and reflected light is conspicuously viewed [30, 31].

As expected, the instrumental color analysis showed significantly $(p<0.05)$ higher $a^{*}$ values and lower $b^{*}$ values for 

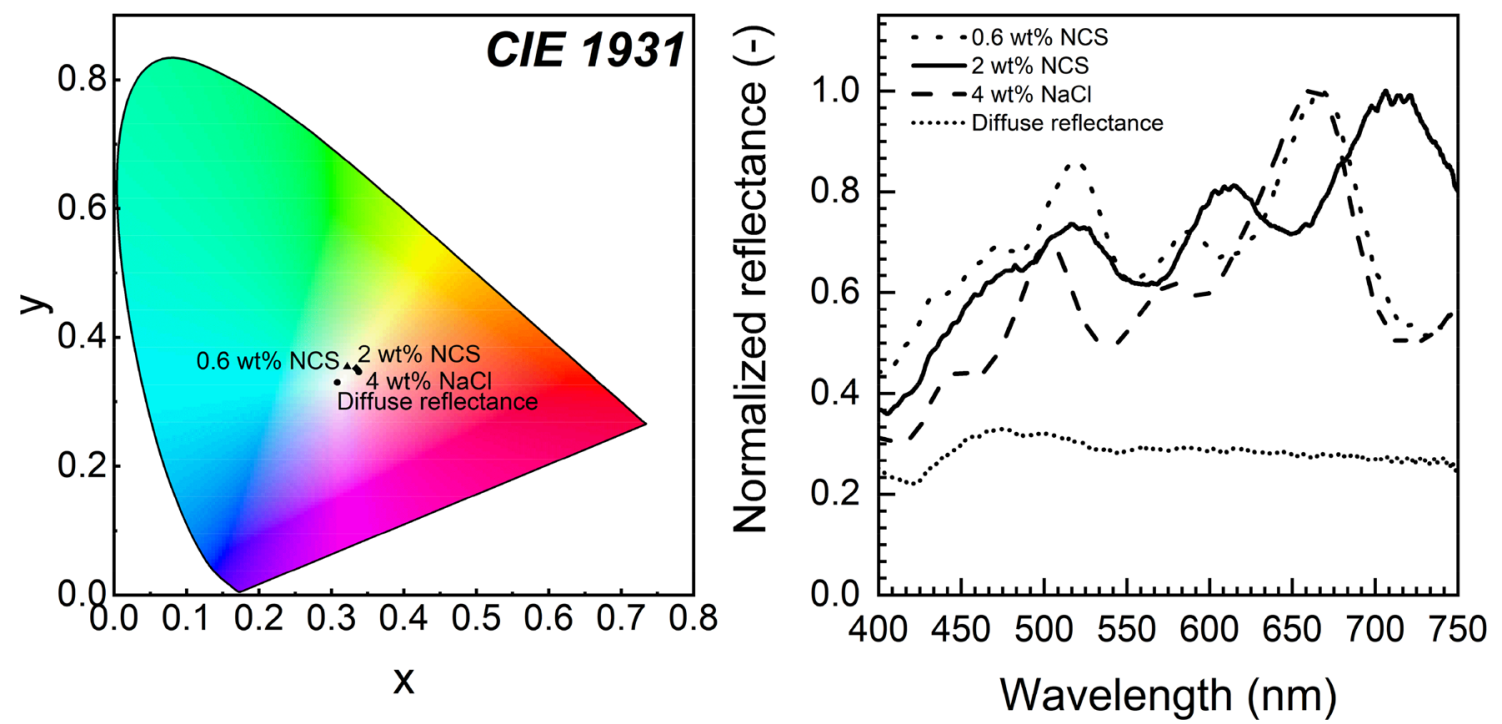

Fig. 5 Interference colors (illustrated in the CIE 1931 chromaticity diagram) and normalized reflectance spectra of iridescent areas from cooked samples treated with $0.6 \mathrm{wt} \%, 2 \mathrm{wt} \%$ curing salt (NCS) or $4 \mathrm{wt} \% \mathrm{NaCl}$

the NCS treatments indicating redder sample colors compared to the yellowish color of the $\mathrm{NaCl}$ treatments and the control samples. What is interesting about the color data is that lightness $L^{*}$ in control samples was higher. Lightness is attributed to achromatically light scattering by a microstructure, hence higher lightness values correlate to a higher extent of incoherent light scattering [32]. Since structural colors in general and meat iridescence in particular are the result of an interaction of light with periodic nano- or microstructures causing colors by interference or coherent scattering, an increase in incoherent light scattering due to, e.g., changes in the microstructure could have had a suppressive effect on meat iridescence. In our experiment, a higher $L^{*}$ value was measured in the control samples compared to the salt-treated samples. These results suggest that incoherent light scattering decreased with the addition of salt and further support the idea of Swatland [33], who hypothesized that iridescence is lost when scattering is strong.

But what is affecting incoherent scattering in meat and meat products and thereby iridescence? According to Hughes, Clarke [32] and Purslow, Warner [34], differences in light scattering arise from variations in transverse shrinkage of the structural lattice of myofilaments, myofibrils and muscle fibers, longitudinal shrinkage of the sarcomere with changes in the protein density of A- and I-bands, and different protein composition of the sarcoplasm and extracellular space. Although the sarcomere length per se has little or no relationship to the appearance of iridescence [35], other microstructural factors may be associated with meat iridescence. Structural changes of the muscle tissue occur mainly through desolubilization and aggregation of the myofibrillar proteins [36] and can be induced by numerous factors, including $\mathrm{pH}$ shift, heat treatment and salt addition. Previous research [16, 37-39] has shown that the interfilament lattice spacing is due to electrostatic repulsion between the myofibrillar proteins and that with the addition of salts myofibril swelling occurs. Offer and Trinick [37] explained the saltinduced swelling with a combination of the selective binding of chloride ions to the filaments and thereby increasing the electrostatic repulsive forces and the removal of transverse structural constraints (actomyosin cross-bridges, M-line, Z-line). In addition, Wilding Wilding, Hedges [17] showed that the swelling only occurred in the fiber transverse plane. The salt-induced swelling of myofibers might thus be an explanation for the observed increased iridescence in salttreated samples. Since light scattering occurs by diffraction through the myofilament lattice or from the edges of myofibrils, the swelling reduces incoherent scattering than rough widening of the lattice and a reduction of intermyofibrillar spaces. This reduction of scattering could then give rise to stronger light interference causing more intense iridescent colors. It might also be possible that the myofibers and fiber bundles are packed more closely together with less extracellular spaces and thereby a higher amount of the incoming light could pass along individual fibers and cause iridescence. This might increase the iridescence extent from a macroscopic perspective.

Salt-induced swelling and lower cooking losses were also observed in our study. As expected, cooking loss was highest in the control samples and decreased successive with higher salt contents. However, the water content was similar in all cooked samples $(p>0.05)$ and could, therefore, not explain the differences in iridescence. This observation is in accordance with Wang [7] who found only a weak relationship 
between iridescence and water content in both raw and cooked beef semitendinosus muscles. Besides, interference colors appear in products with varying water contents, e.g., in fresh meat with a water content of about $75 \%$ as well as in dry cured hams with a water content of about $40 \%$. On the other hand, the hydration state of meat has been attributed to the occurrence of iridescence [35] and it has been shown that drying reduced or even eliminated iridescence [7, 11]. This process is reversible and might again be explained by changes in myofibril swelling and shrinkage [40]. This provides further evidence that iridescence may be related to a structural aspect, i.e., myofibril swelling, which in turn affects water-binding capacity.

As can be seen from Fig. 6, the mean fiber diameter increased with the addition of salt from $54.15 \pm 7.44 \mu \mathrm{m}$ for the control samples to $64.57 \pm 3.73 \mu \mathrm{m}$ for the $2 \% \mathrm{NaCl}$ treatment (Table 1). However, Feret diameter of the control only differed significantly from the samples treated with $2 \%$ and $4 \% \mathrm{NaCl}$, respectively $4 \% \mathrm{NCS}$. These results are in general agreement with the sensory analysis where stronger iridescence was observed with the addition of salt, but where eventually a maximum iridescence score was reached above which a further increase of salt concentration did not cause stronger iridescence. The observed limit in iridescence increase may be explained by that fact that myofibrils cannot swell unlimited. Rather, swelling is restricted by structural constraints, e.g., presence of Z-line, actomyosin crossbridges and intermediate filaments [18, 37]. Indeed, in our study, mean fiber diameters increased and at the same time, iridescence became stronger with higher salt concentrations, but eventually a limit was reached for both, and no further swelling or stronger iridescence occurred beyond that.

Taken together, statistical analysis of the measured data indicated that there was a significant correlation between iridescence and cooking loss $\left(r_{\mathrm{s}}=-0.668, p<0.01\right)$, mean fiber diameter $\left(r_{\mathrm{s}}=0.538, p<0.05\right)$ and salt content $\left(r_{\mathrm{s}}=0.721, p<0.05\right)$. The findings of this study thus support the assumptions that iridescence originates from reflections at the myofilament lattice and might be directly related to the lattice spacing. It should be noted though that the occurrence of iridescence cannot be attributed to certain specific myofiber diameters and lattice spacing since iridescence was also observed in control samples. Moreover, it seems that the intensifying of iridescence with salt cannot only be explained with the lattice swelling since the degree of swelling also depends on $\mathrm{pH}$. For example, in the presence of salt, maximum swelling occurs at $\mathrm{pH} 6.0$ [16]. Therefore, with the explanation of stronger iridescence caused by swelling and thus reduced scattering, iridescence should be associated with high $\mathrm{pH}$ values [33]. But previous studies have found lower iridescence in dark cutting carcasses (characterized by high $\mathrm{pH}$ and high water-holding capacity) [2], stronger iridescence in PSE cooked ham [41], and a weak
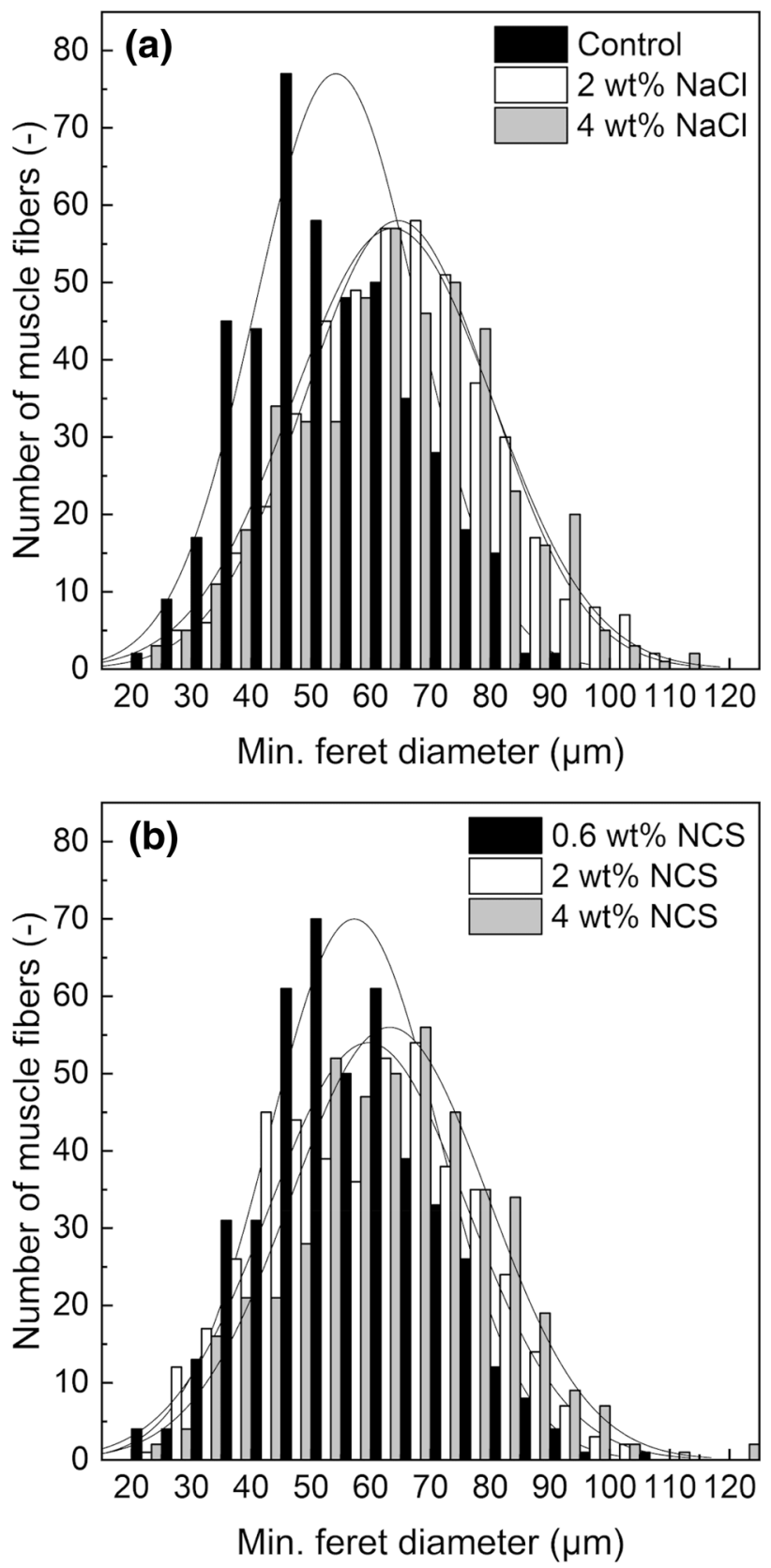

Fig. 6 Histograms of the mean fiber diameter (shown as minimal Feret diameter) for cooked samples from pork M. longissimus thoracis et lumborum treated with different salting treatments (NCS: curing salt, final nitrite concentration of the NCS samples was constant at $0.01 \mathrm{~g} \mathrm{NaNO}_{2}$ per $100 \mathrm{~g}$ of fresh meat)

relationship between iridescence and $\mathrm{pH}$ in raw and cooked meat [7] (Table 2).

This highlights that sodium chloride has a very complex effect on different meat proteins and thereby on the meat microstructure. The myofibrillar proteins (including actin, myosin, tropomyosin, and troponin) are classified as saltsoluble proteins and solubility monotonically increases 
Table 1 Physicochemical and colorimetric parameters of cooked samples $(n=3)$ from pork M. longissimus thoracis et lumborum with different salting treatments (sodium chloride or nitrite curing salt; the nitrite concentration of the curing salts were adjusted to achieve a constant final nitrite concentration of $0.01 \mathrm{~g} \mathrm{NaNO}_{2} / 100 \mathrm{~g}$ fresh meat: $0.6 \mathrm{wt} \%$ (16.7 $\mathrm{g} \mathrm{NaNO}_{2}$ per $\mathrm{kg}$ salt), $2 \mathrm{wt} \%$ ( $5 \mathrm{~g} \mathrm{NaNO}_{2}$ per kg salt), $4 \mathrm{wt} \%\left(2.5 \mathrm{~g} \mathrm{NaNO}_{2}\right.$ per kg salt))

\begin{tabular}{|c|c|c|c|c|c|c|}
\hline & \multirow[t]{3}{*}{ Control } & \multicolumn{5}{|c|}{ Salting treatment } \\
\hline & & \multicolumn{2}{|l|}{ Sodium chloride } & \multicolumn{3}{|c|}{ Nitrite curing salt } \\
\hline & & $2 \mathrm{wt} \%$ & $4 \mathrm{wt} \%$ & $0.6 \mathrm{wt} \%$ & $2 \mathrm{wt} \%$ & $4 \mathrm{wt} \%$ \\
\hline $\mathrm{pH}(-)$ cooked samples & $5.69 \pm 0.12^{\mathrm{a}}$ & $5.67 \pm 0.02^{\mathrm{a}}$ & $5.75 \pm 0.04^{\mathrm{a}}$ & $5.74 \pm 0.09^{\mathrm{a}}$ & $5.72 \pm 0.03^{\mathrm{a}}$ & $5.74 \pm 0.04^{\mathrm{a}}$ \\
\hline Cooking loss (wt $\%)$ & $22.4 \pm 1.0^{\mathrm{a}}$ & $17.2 \pm 3.1^{\mathrm{a}}$ & $15.4 \pm 0.8^{\mathrm{b}}$ & $20.1 \pm 1.6^{\mathrm{a}}$ & $19.1 \pm 2.0^{\mathrm{a}}$ & $13.9 \pm 0.4^{\mathrm{b}}$ \\
\hline Water (wt $\%)$ & $67.6 \pm 0.3^{\mathrm{a}}$ & $68.6 \pm 0.7^{\mathrm{a}}$ & $68.0 \pm 0.3^{\mathrm{a}}$ & $68.1 \pm 0.8^{\mathrm{a}}$ & $68.7 \pm 0.5^{\mathrm{a}}$ & $68.2 \pm 0.4^{\mathrm{a}}$ \\
\hline Protein $(w t \%)$ & $29.8 \pm 0.7^{\mathrm{a}}$ & $28.1 \pm 0.7^{\mathrm{a}}$ & $27.7 \pm 0.4^{\mathrm{a}}$ & $29.5 \pm 1.4^{\mathrm{a}}$ & $27.7 \pm 1.4^{\mathrm{a}}$ & $28.8 \pm 2.4^{\mathrm{a}}$ \\
\hline $\mathrm{NaCl}(\mathrm{wt} \%)$ & - & $1.71 \pm 0.08^{\mathrm{a}}$ & $2.82 \pm 0.14^{\mathrm{b}}$ & $0.68 \pm 0.04^{c}$ & $1.64 \pm 0.09^{\mathrm{a}}$ & $2.87 \pm 0.26^{\mathrm{a}}$ \\
\hline$L^{*}(-)$ & $74.38 \pm 1.60^{\mathrm{a}}$ & $70.10 \pm 2.25^{\mathrm{bc}}$ & $69.16 \pm 2.41^{\mathrm{bc}}$ & $71.18 \pm 3.06^{\mathrm{b}}$ & $69.29 \pm 2.20^{\mathrm{bc}}$ & $66.89 \pm 1.67^{\mathrm{bc}}$ \\
\hline$a^{*}(-)$ & $3.59 \pm 0.70^{\mathrm{a}}$ & $2.79 \pm 1.01^{\mathrm{a}}$ & $2.54 \pm 0.47^{\mathrm{a}}$ & $9.42 \pm 1.94^{\mathrm{b}}$ & $8.31 \pm 1.04^{\mathrm{b}}$ & $8.82 \pm 1.08^{\mathrm{b}}$ \\
\hline$b^{*}(-)$ & $10.45 \pm 0.37^{\mathrm{a}}$ & $8.70 \pm 0.57^{\mathrm{c}}$ & $8.88 \pm 0.22^{\mathrm{c}}$ & $6.29 \pm 0.27^{\mathrm{b}}$ & $5.90 \pm 0.50^{\mathrm{b}}$ & $5.77 \pm 0.44^{\mathrm{b}}$ \\
\hline Min. Feret diameter $(\mu \mathrm{m})$ & $54.15 \pm 7.44^{\mathrm{a}}$ & $64.57 \pm 3.73^{\mathrm{bc}}$ & $63.66 \pm 6.26^{\mathrm{bc}}$ & $57.22 \pm 2.13^{\mathrm{ac}}$ & $59.59 \pm 3.04^{\mathrm{ac}}$ & $63.15 \pm 2.83^{\mathrm{bc}}$ \\
\hline
\end{tabular}

Data points with different letters in the same row are significantly different $(p<0.05)$

with increasing $\mathrm{NaCl}$ concentrations [42], an effect known as "salting-in". However, the solubility characteristics of myosin and actin are very different [18] and it is only the myosin that is dissolved by salt. It has been shown that even with high salt concentrations $(2.4 \mathrm{M} \mathrm{NaCl})$, the actin filaments are not dissolved [43]. Thus, if one considers effects of salt on meat structure, sodium chloride extracts the A-band, Z-disc and disrupts structures in the M-line $[18,24,38,44]$. Substantial extraction of the A-band and Z-disc was observed in myofibrils in $1.0 \mathrm{M} \mathrm{NaCl}$ solutions and it is known that maximum dissociation of protein assemblies (salting-in) occurs at $\mathrm{NaCl}$ concentrations around $1 \mathrm{M}$ [44]. As aforementioned, structural components, such as the myofilament lattice and refractive index boundaries between sarcoplasm and myofibrils cause light scattering and thereby may restrain meat iridescence which has been shown to originate from Fresnel

Table 2 Spearman's correlation coefficient $\left(r_{s}\right)$ calculated between iridescence score and $\mathrm{pH}$, cooking loss, water content, $\mathrm{NaCl}$ content, colorimeter values and min. Feret diameter

\begin{tabular}{lcl}
\hline Variable & $\begin{array}{l}\text { Correlation coeffi- } \\
\text { cient } r_{\mathrm{s}}\end{array}$ & $p$ \\
\hline $\mathrm{pH}$ & 0.024 & 0.925 \\
Cooking loss $(\%)$ & $0.668^{* *}$ & 0.002 \\
Water content $(\%)$ & 0.324 & 0.190 \\
$\mathrm{NaCl}(\%)$ & $0.721^{* *}$ & 0.001 \\
$L^{*}$ & $-0.583^{*}$ & 0.011 \\
$a^{*}$ & -0.220 & 0.381 \\
$b^{*}$ & -0.296 & 0.232 \\
Min. Feret diameter $(\mu \mathrm{m})$ & $0.538^{*}$ & 0.021 \\
\hline
\end{tabular}

${ }^{*} p<0.01 ; * * p<0.05$ reflectance [3]. Swatland and Barbut [45] investigated the effect of sodium chloride levels on Fresnel reflectance with a polarimetric probe and demonstrated that lightness $L^{*}$ decreased in comminuted chicken samples with increasing $\mathrm{NaCl}$ concentrations from 0 to $2 \%$ and that the decrease in lightness was associated with an increase in the relative amount of reflected light maintaining its original plane of polarization (Fresnel reflectance). The authors suggested that light scattering might be reduced due to the dissolution of myofibrillar proteins and allow more Fresnel reflectance to be detected. Thus, dissolution of myofibrillar proteins might be another factor contributing to iridescence increase with increased $\mathrm{NaCl}$ concentrations. Clearly, light scattering and iridescence in meat are extremely complex phenomena and the microstructural causes are still to a large part unknown. It is likely that there are several mechanisms involved in the iridescence increase and the presented explanations (myofibril swelling and myofibrillar protein extraction) are only a part of the involved mechanism.

Further research might, therefore, want to look at the effect of different salts to gain a better understanding of the mechanisms involved in meat iridescence. Different salts can be classified according to their ability to increase or decrease the solubility of proteins in aqueous media (Hofmeister series). The Hofmeister series has an effect on the ion distribution of actin and myosin filaments, their stability and the water-holding capacity of meat follows the lyotropic series [18]. The use of a well-defined set of kosmo- and chaotropic salts may, therefore, be a valuable approach to further clarify the underlying mechanism. 


\section{Conclusion}

The aim of the present research was to examine the influence of various salt concentrations on meat iridescence in cooked pork products. The results of this study showed that $\mathrm{NaCl}$ had a significant intensifying effect on surface iridescence. Higher iridescence scores were associated with higher salt concentrations, larger myofibers diameters, and lower cooking losses but iridescence was limited to a certain degree. Moreover, the addition of nitrite and thereby the reddening of the samples had no effect on both the interference colors and the macroscopic visual perception of iridescence indicating that the pigmentary color is of no importance for meat iridescence. From a practical point of view, though, one has to state that these findings show that addition of salt offers only a limited opportunity to reduce or inhibit iridescence in meat products, since the production of meat products at very low or very high salt concentrations is not feasible. A more promising way forward may be to use different salts to manipulate the muscle fiber and thus light scattering and interference, an approach that is also useful as part of a sodium nitrite reduction strategy.

Acknowledgements This research project was financially supported by the German Ministry of Economics and Energy (via AiF) and the FEI (Forschungskreis der Ernährungsindustrie e.V., Bonn), Project AiF $20011 \mathrm{~N}$

Author contributions JW: conceptualization, project administration, supervision, funding acquisition, and writing - reviewing and editing. MG: conceptualization, project administration, validation, funding acquisition, and writing - reviewing and editing. CR: conceptualization, methodology, formal analysis, investigation, writing-original draft, and visualization.

Funding Open Access funding enabled and organized by Projekt DEAL. This research project was financially supported by the German Ministry of Economics and Energy (via AiF) and the FEI (Forschungskreis der Ernährungsindustrie e.V., Bonn), Project AiF 20011N.

Data availability The data that support the findings of this study are available from the corresponding author, Jochen Weiss, upon reasonable request.

Code availability Not applicable.

\section{Declarations}

Conflict of interest All the authors declare that they have no competing interests.

Ethical approval This article does not contain any studies with human participants or animals performed by any of the authors.

Open Access This article is licensed under a Creative Commons Attribution 4.0 International License, which permits use, sharing, adaptation, distribution and reproduction in any medium or format, as long as you give appropriate credit to the original author(s) and the source, provide a link to the Creative Commons licence, and indicate if changes were made. The images or other third party material in this article are included in the article's Creative Commons licence, unless indicated otherwise in a credit line to the material. If material is not included in the article's Creative Commons licence and your intended use is not permitted by statutory regulation or exceeds the permitted use, you will need to obtain permission directly from the copyright holder. To view a copy of this licence, visit http://creativecommons. org/licenses/by/4.0/.

\section{References}

1. Swatland HJ (2018) Iridescence in cooked venison-an optical phenomenon. J Nutr Health Food Eng 8(2):105-108. https://doi. org/10.15406/jnhfe.2018.08.00264

2. Kukowski AC et al (2004) Factors associated with surface iridescence in fresh beef. Meat Sci 66(4):889-893. https://doi.org/10. 1016/j.meatsci.2003.08.011

3. Swatland HJ (2012) Iridescence in beef caused by multilayer interference from sarcomere discs. Meat Sci 90(2):398-401. https:// doi.org/10.1016/j.meatsci.2011.08.006

4. Swatland HJ (2012) Muscle iridescence in yellowfin tuna (Thunnus albacares). Food Res Int 48(2):449-453. https://doi.org/10. 1016/j.foodres.2012.05.018

5. Totosaus A, Pérez-Chabela ML, Guerrero I (2007) Color of fresh and frozen poultry, in handbook of meat. Poult Seafood Qual 2007:455-466

6. Swatland HJ (1984) Optical characteristics of natural iridescence in meat. J Food Sci 49(3):685-686. https://doi.org/10.1111/j. 1365-2621.1984.tb13188.x

7. Wang H (1991) Causes and solutions of iridescence in precooked meat. Ph.D. dissertation. Kansas State University, Manhatten

8. Kinoshita S, Yoshioka S (2005) Structural colors in nature: the role of regularity and irregularity in the structure. ChemPhysChem 6(8):1442-1459. https://doi.org/10.1002/cphc.200500007

9. Ockerman HW (1996) Chemistry of meat tissue. Dept. of Animal Science, Ohio State University, Ohio

10. Warriss PD (2001) Meat science. An introductory text. Cabi Pub Inc, New York

11. Martinez-Hurtado JL, Akram MS, Yetisen AK (2013) Iridescence in meat caused by surface gratings. Foods 2(4):499-506

12. Swatland HJ (2018) Fascinating iridescence. http://www.cmsaascv.ca/library.html

13. Swatland HJ (2017) On wetting muscovy glass and a peacock feather, following Robert Hooke to investigate the colourimetry of meat iridescence. Quekett J Microsc 43:125-130

14. Ruedt $\mathrm{C}$ et al (2021) Colour change with longitudinal compression supports hypothesis of multilayer interference as cause for meat iridescence. Int J Food Sci Technol 56(1):250-258. https://doi. org/10.1111/ijfs. 14626

15. Inguglia ES et al (2017) Salt reduction strategies in processed meat products—a review. Trends Food Sci Technol 59:70-78. https://doi.org/10.1016/j.tifs.2016.10.016

16. Hamm R (1972) Kolloidchemie des Fleisches. Das Wasserbindungsvermögen des Muskeleiweißes in Theorie und Praxis. Nahrung-food, vol 16. Paul Parey, Berlin, pp 689-690

17. Wilding P, Hedges N, Lillford PJ (1986) Salt-induced swelling of meat: The effect of storage time, $\mathrm{pH}$, ion-type and concentration. Meat Sci 18(1):55-75. https://doi.org/10.1016/0309-1740(86) 90066-5 
18. Puolanne E, Halonen M (2010) Theoretical aspects of water-holding in meat. Meat Sci 86(1):151-165. https://doi.org/10.1016/j. meatsci.2010.04.038

19. Fudouzi H (2011) Tunable structural color in organisms and photonic materials for design of bioinspired materials. Sci Technol Adv Mater 12(6):064704. https://doi.org/10.1088/1468-6996/ $12 / 6 / 064704$

20. Senser F, Souci SW, Lebensmittelchemie DFF (1991) Der kleine "Souci-Fachmann-Kraut": Lebensmitteltabelle für die Praxis. Wissenschaftliche Verlagsgesellschaft

21. Schindelin J et al (2012) Fiji: an open-source platform for biological-image analysis. Nat Methods 9(7):676-682. https://doi.org/ 10.1038/nmeth.2019

22. CIE (1976) Colorimetry-Part 4: CIE 1976 L*A*B* colour space. ISO/CIE 11664-4:2019

23. BVL (2005) Amtliche Sammlung von Untersuchungsverfahren nach § 64 LFGB. Beuth Verlag GmbH, Berlin

24. Katsaras K, Budras K-D (1993) The relationship of the microstructure of cooked ham to its properties and quality. LWT Food Sci Technol 26(3):229-234. https://doi.org/10.1006/fstl.1993. 1050

25. Huang $F$ et al (2011) Influence of heat on protein degradation, ultrastructure and eating quality indicators of pork. J Sci Food Agric 91(3):443-448. https://doi.org/10.1002/jsfa.4204

26. Jaint $\mathrm{N}$ et al (2010) Gender based alteration in color perception. Indian J Physiol Pharmacol 54(4):366-370

27. Knoblauch K et al (1987) Age and illuminance effects in the Farnsworth-Munsell 100-hue test. Appl Opt 26(8):1441-1448

28. Wang, H., et al. (1990) Effects of processing variables on iridescence in precooked beef.

29. Swatland HJ (2019) Colourimetry of iridescent muscle fibers. Quekett J Microscopy 43:357-362

30. Miyamoto K, Kosaku A (2002) Cuticular microstructures and their relationship to structural color in the shieldbug Poecilocoris lewisi Distant. FORMA-TOKYO 17(2):155-167

31. Fox DL (1976) Animal biochromes and structural colours: physical, chemical, distributional \& physiological features of coloured bodies in the animal world. Univ of California Press, California

32. Hughes JM et al (2020) Meat color is determined not only by chromatic heme pigments but also by the physical structure and achromatic light scattering properties of the muscle. Comp Rev Food Sci Food Saf 19(1):44-63. https://doi.org/10.1111/15414337.12509

33. Swatland HJ (2012) Optical properties of meat. In: Proceedings of the 65th reciprocal meat conference

34. Purslow PP et al (2020) Variations in meat colour due to factors other than myoglobin chemistry; a synthesis of recent findings

\section{Authors and Affiliations}

\section{Chiara Ruedt ${ }^{1}$ (I) $\cdot$ Monika Gibis $^{1} \cdot$ Jochen Weiss $^{1}$}

\section{Jochen Weiss}

j.weiss@uni-hohenheim.de (invited review). Meat Sci 159:107941. https://doi.org/10.1016/j. meatsci.2019.107941

35. Swatland HJ (1988) Interference colors of beef fasciculi in circularly polarized light. J Anim Sci 66(2):379. https://doi.org/10. 2527/jas1988.662379x

36. Böcker $U$ et al (2006) Salt-induced changes in pork myofibrillar tissue investigated by FT-IR microspectroscopy and light microscopy. J Agric Food Chem 54(18):6733-6740. https://doi.org/10. 1021/jf060178q

37. Offer G, Trinick J (1983) On the mechanism of water holding in meat: the swelling and shrinking of myofibrils. Meat Sci 8(4):245-281. https://doi.org/10.1016/0309-1740(83)90013-X

38. Voyle C, Jolley P, Offer G (1984) The effect of salt and pyrophosphate on the structure of meat. Food Struct 3(2):3

39. Bertram HC, Purslow PP, Andersen HJ (2002) Relationship between meat structure, water mobility, and distribution: a lowfield nuclear magnetic resonance study. J Agric Food Chem 50(4):824-829. https://doi.org/10.1021/jf010738f

40. Mancini R (2007) Iridescence: a rainbow of colors, causes, and concerns. Beef facts: product enhancement, pp 1-4

41. Oliver MA et al (2006) Effect of natural stabilised pork haem pigment on the colour, colour stability and texture of cooked hams from pale, soft and exudative meat. Food Sci Technol Int 12(5):429-435. https://doi.org/10.1177/1082013206070161

42. Wu L et al (2016) Effects of cations on the "salt in" of myofibrillar proteins. Food Hydrocolloids 58:179-183. https://doi.org/10. 1016/j.foodhyd.2016.02.028

43. Offer G, Knight P (1988) The structural basis of water-holding in meat. Part I: General principles and water uptake in meat processing. In: Lawrie RA (ed) Developments in meat science-4. Elsevier, London, pp 63-343

44. Knight $\mathrm{P}$, Parsons $\mathrm{N}$ (1988) Action of $\mathrm{NaCl}$ and polyphosphates in meat processing: responses of myofibrils to concentrated salt solutions. Meat Sci 24(4):275-300. https://doi.org/10.1016/03091740(88)90040-X

45. Swatland HJ, Barbut S (1999) Sodium chloride levels in comminuted chicken muscle in relation to processing characteristics and Fresnel reflectance detected with a polarimetric probe. Meat Sci 51(4):377-381. https://doi.org/10.1016/S0309-1740(98)00138-7

Publisher's Note Springer Nature remains neutral with regard to jurisdictional claims in published maps and institutional affiliations.

1 Department of Food Material Science, Institute of Food Science and Biotechnology, University of Hohenheim, Garbenstraße 21/25, 70599 Stuttgart, Germany 